\title{
Исследование спонтанной эмиссии в брэгговских монослойных квантовых ямах InAs
}

\author{
(C) Г. Позина ${ }^{1}$, М.А. Калитеевский ${ }^{2,3,4}$, Е.В. Никитина ${ }^{2,3, \text { ฯ А.Р. Губайдуллин }}{ }^{2,4}$, \\ К.А. Иванов ${ }^{2,4}$, А.Ю. Егоров ${ }^{3,4}$ \\ ${ }^{1}$ Department of Physics, Chemistry and Biology (IFM), Linkoping University, \\ S-58183 Linkoping, Sweden \\ ${ }^{2}$ Санкт-Петербургский Академический университет Российской академии наук, \\ 194021 Санкт-Петербург, Россия \\ ${ }^{3}$ Физико-технический институт им. А.Ф. Иофффе Российской академии наук, \\ 194021 Санкт-Петербург, Россия \\ ${ }^{4}$ Университет ИТМО, \\ 197101 Санкт-Петербург, Россия \\ ๑ E-mail: E.Nikitina@mail.ioffe.ru
}

(Получена 14 декабря 2017 г. Принята к печати 22 декабря 2017 г.)

\begin{abstract}
Экспериментально исследована фотолюминесценция с временнб́м разрешением структуры брэгговских монослойных квантовых ям InAs в матрице GaAs. Путем сравнения спектров фотолюминесценции, измеренных с торца и с поверхности образца, установлено, что брэгговское упорядочение квантовых ям приводит к существенному изменению спектров фотолюминесценции, в частности к появлению дополнительных мод. Спектр фотолюминесценции, измеренный с торца образца, содержит одну линию, соответствующую основному состоянию экситона. В спектре излучения, измеренном с поверхности образца, при высоких уровнях возбуждения появляется дополнительная линия излучения, частота и направление распространения которой соответствуют брэгговскому условию для квантовых ям. Проведенный расчет модового фактора Парселла объясняет факт усиления спонтанной эмиссии излучения только для определенных углов распространения и частот излучения, а не для всех направлений распространения и частот, удовлетворяющих брэгговскому условию.
\end{abstract}

DOI: $10.21883 /$ FTP.2018.07.46044.8801

\section{1. Введение}

Известно, что при распространении электромагнитных волн в неоднородных средах возможны эффекты усиления [1] и подавления [2] спонтанной эмиссии света. Понимание природы этих процессов и их точное количественное описание необходимы для создания эффективных полупроводниковых устройств. Важное место среди таких устройств занимают периодические структуры различной природы [3].

В последние годы существенное внимание уделяется резонансным брэгговским структурам [4], в которых периодическая модуляция диэлектрической проницаемости достижима с помощью экситонных состояний в квантовых ямах (КЯ) [5-7], а квантовые ямы располагаются с периодом $d$, который соответствует резонансному брэгговскому условию

$$
\hbar \omega_{0}=\frac{\pi \hbar c}{d \sqrt{n^{2}-\sin ^{2} \theta}},
$$

где $n-$ показатель преломления слоистой среды, $\theta-$ угол распространения волны на частоте экситонного резонанса $\omega_{0}$. Ряд интересных эффектов, например резонансное отражение света брэгговскими структурами, был предсказан более 20 лет назад [5], однако экспериментально данный эффект получен сравнительно недавно [8]. Кроме этого, недавно был показан эффект усиления спонтанной эмиссии света и появления сверхизлучательной моды в брэгговских монослойных квантовых ямах (BMQW) [9,10]. Интересно отметить, что в [9] дополнительная сверхизлучательная мода обладала наибольшей интенсивностью для значений угла эмиссии в интервале от 40 до $50^{\circ}$. Таким образом, помимо брэгговского условия (1) существует некоторое дополнительное условие, определяющее интенсивность сверхизлучательной моды.

Эффект сверхизлучения, теоретически предсказанный Dicke [11], заключается в том, что одинаковые эмиттеры излучают не независимо, а взаимодействуют через электромагнитное поле, что может приводить, в частности, к эффекту суперлюминесценции, характеризуемому квадратичной зависимостью интенсивности излучения $I$ от накачки $P$. Сверхлинейная зависимость интенсивности излучения от накачки, обнаруженная в $[9,10]$, позволила авторам этих работ предположить, что дополнительные линии в спектре, появляюшиеся при больших интенсивностях накачки, являются сверхизлучательными модами. Вместе с тем, чтобы сделать однозначный вывод о наличии сверхизлучения, необходимо исключить другие объяснения сверхлинейной зависимости $I(P)$. В частности нужно показать, что наблюдаемая сверхлинейность не является следствием релаксации носителей заряда через возбужденные состояния (в $[9,10]$ накачка системы проводилась с помощью пикосекундных лазерных импульсов, и сверхизлучательная мода имеет энергию выше, чем основное состояние экситона). Для разреше- 

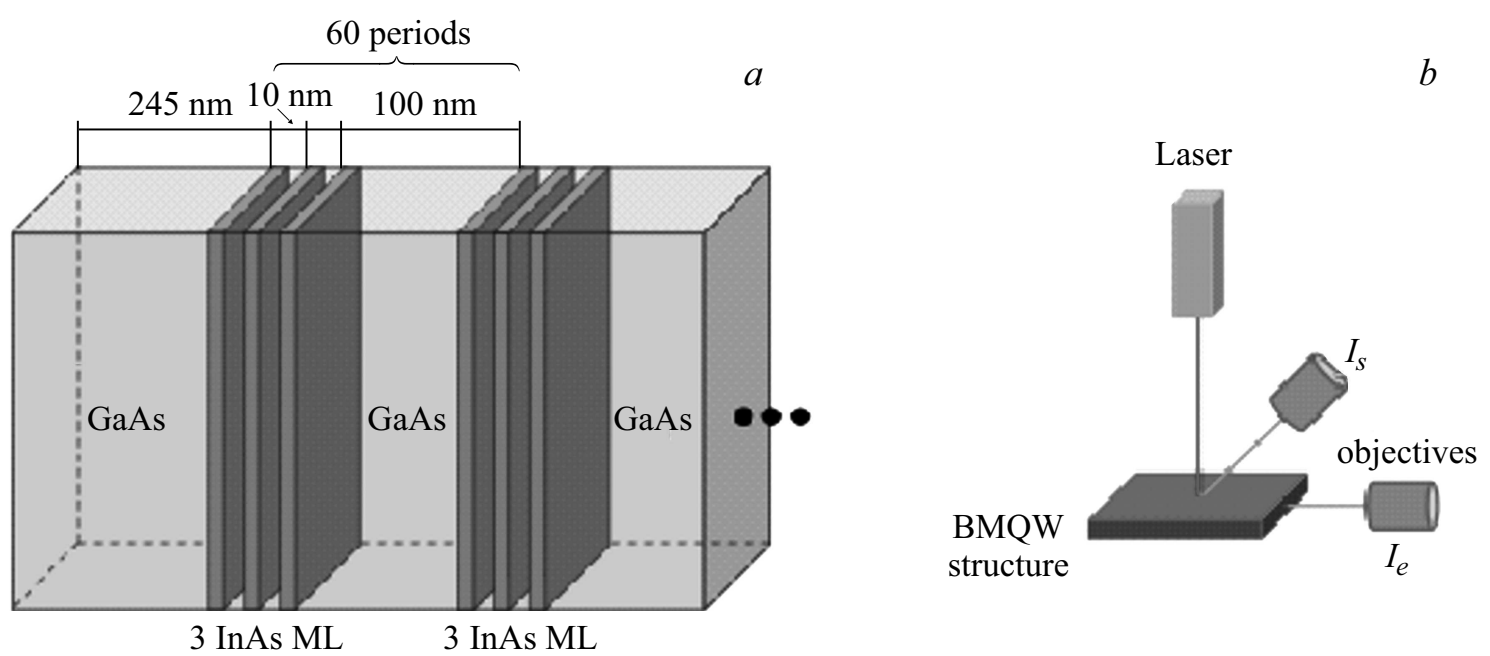

Рис. 1. Схематическое изображение структуры $(a)$ и схема экспериментальных измерений $(b)$.

ния этого вопроса в данной работе проводились одновременно измерения спонтанной эмиссии излучения с поверхности структуры $\left(I_{s}\right)$ и ее торца $\left(I_{e}\right)$, а также теоретически исследовались зависимости коэффициента отражения и модового коэффициента Парселла [12] от угла и частоты света.

\section{2. Результаты и обсуждение}

Исследуемая структура выращена методом молекулярно-пучковой эпитаксии с использованием эпитаксиальной установки Riber 49 на подложке GaAs ориентации (100). Для достижения однородности структуры был проведен процесс роста на вращающейся подложке. Образец выращивался при температуре $570^{\circ} \mathrm{C}$ и скорости роста $1.8 \AA / \mathrm{c}$.

Схема структуры представлена на рис. $1, a$. Структура содержит 60 периодов, активная область в каждом периоде состоит из трех монослоев (ML) InAs, разделенных барьерами GaAs толщиной 10 нм, активные области разделены слоями нелегированного GaAs толщиной $\sim 100$ нм. В такой структуре реализуются 3 экситонных резонанса, с энергиями $1.471,1.482$ и 1.491 эВ. По своим параметрам структура близка к структурам, исследованным в $[9,10]$, однако в нашем случае использовался другой образец. Была разработана структура, в которой брэгговское условие при нормальном распространении света должно выполняться для энергии фотона 1.47 эВ при температуре $5 \mathrm{~K}$.

Толщина покрывающего слоя GaAs была выбрана 245 нм, чтобы обеспечить согласование пучностей электрического поля коллективной сверхизлучательной моды в активных областях. Часть покрывающего слоя $\mathrm{GaAs}$ вблизи поверхности образца была легирована $\mathrm{Si}$ с концентрацией $4 \cdot 10^{18} \mathrm{~cm}^{-3}$, чтобы избежать экситонной особенности в спектре отражения от поверхности образца.
Исследование фотолюминесценции (ФЛ) с временны́м разрешением (ФЛВР) проведено при оптической накачке фемтосекундным лазером Ti: sapphire с частотой $75 \mathrm{MГц}$ и длиной волны 800 нм. Измерение ФЛ с временнб́м разрешением $\sim 20$ пс проводилось с помощью электроннооптической камеры Hamamatsu. На рис. 2 приведены спектры ФЛВР, снятые с поверхности образца под углом $40^{\circ}(a)$ и с торца образца $(b)$ при различных интенсивностях накачки - 0.3, 3 и 27 мВт. Выбранному углу наблюдения люминесценции в $40^{\circ}$ соответствует наибольшая интенсивность дополнительной (сверхизлучательной) моды, экспериментально обнаруженной в $[9,10]$.

Можно видеть, что излучение с торца структуры характеризуется одной линией с энергией 1.47 эВ и картина ФЛВР слабо зависит от интенсивности накачки. В то же время картина ФЛВР с поверхности структуры существенно изменяется при изменении накачки. При слабой накачке, картины ФЛВР с поверхности и с торца совпадают, наблюдается одна линия излучения с энергией 1.47 эВ. При увеличении накачки в спектрах излучения, полученных с поверхности образца, появляется дополнительная линия, которая характеризуется временем затухания, существенно меньшим, чем для основного состояния экситона. Такое поведение - изменение картины ФЛВР только при излучении с поверхности, на которое влияет брэгговская интерференция волн, излученных различными квантовыми ямами, - позволяет утверждать, что появление дополнительной моды обусловлено когерентным взаимодействием излучателей в брэгговских квантовых ямах. Для удобства анализа на рис. 2, $c$ приведены спектрально-временны́е зависимости отношения $I_{s} / I_{e}$. Можно видеть, что при слабых накачках особенность на картинах ФЛВР для $I_{s} / I_{e}$ характеризуется фиксированной энергией 1.47 эВ, соответствующей основному состоянию экситона, а при увеличении накачки особенность становится наклонной, что свидетельствует о появлении дополнительных мод в спектре. 

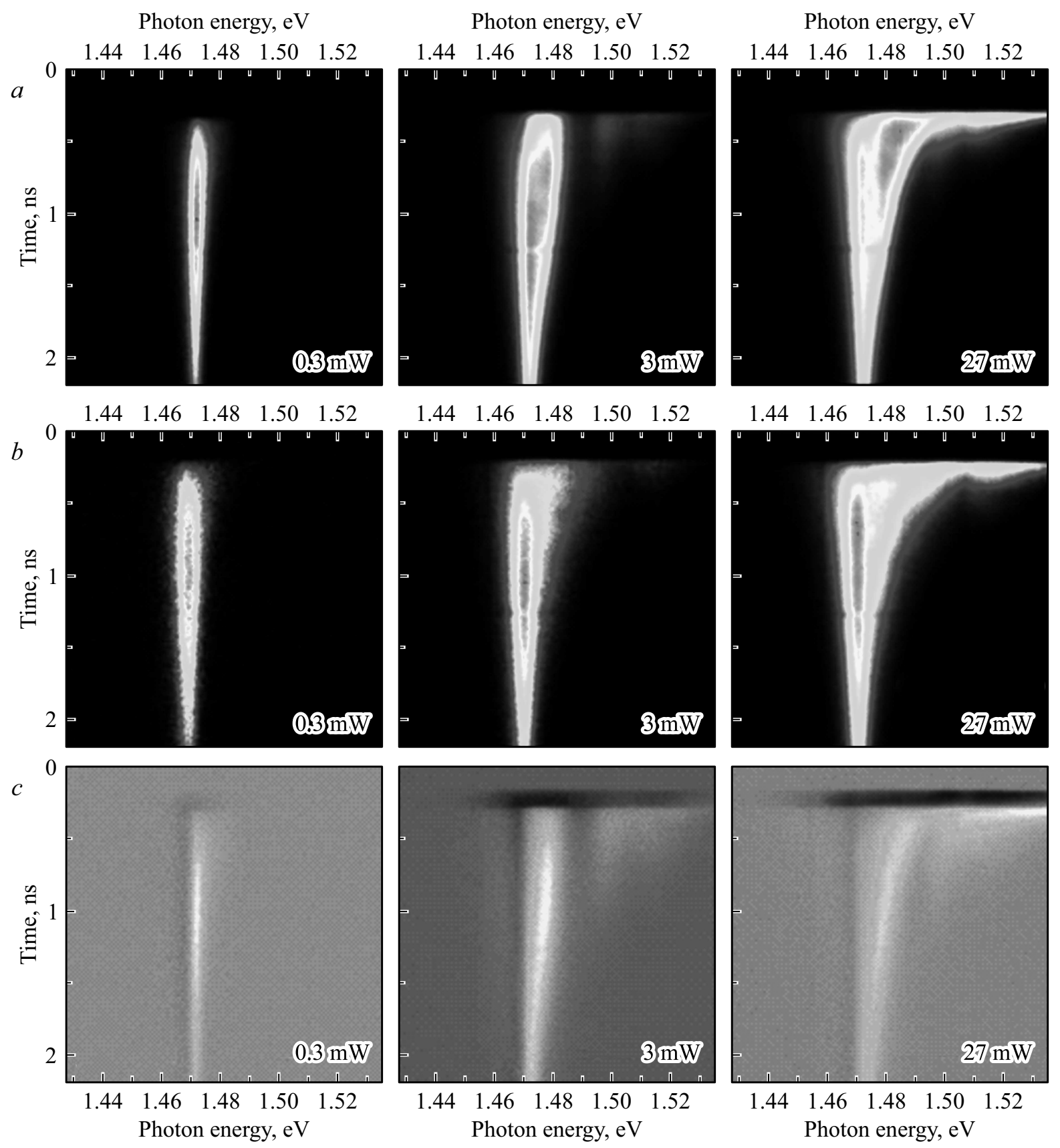

Рис. 2. Изображения фотолюминесценции с временны́м разрешением, измеренные с поверхности $(a)$ и с торца структуры $(b)$. Мощность накачки $0.3,3$ и $27 \mathrm{MB}$. $c$ - отношение интенсивностей фотолюминесценции $I_{s} / I_{e}$, при одинаковых параметрах оптической накачки, измеренных с поверхности (см. $a$ ) и с торца (см. $b$ ) структуры, в логарифмическом масштабе.

Остается открытым вопрос - почему дополнительная „сверхизлучательная мода“ интенсивно проявляет себя в малом интервале углов (от 40 до 50 а не для всей совокупности углов и частот, связанных брэгговским соотношением (1).

На рис. 3, а показана зависимость коэффициента отражения структуры от частоты и угла для света ТЕ-поляризации. На рисунке также приведена зависимость частоты от угла, удовлетворяющая брэгговскому условию (1). Можно видеть, что коэффициент отражения имеет особенности (максимумы и минимумы) вблизи точек на зависимости (1), соответствующих частотам экситонных резонансов. Примеры экспериментально измеренных спектров приведены в $[9,10]$, и можно видеть, что рассчитанная зависимость соответствует экспериментально измеренной.

На рис. $3, b$ показана зависимость модального фактора Парселла (МФП), представляющего собой отношение вероятностей спонтанной эмиссии света определенной частоты в определенном направлении для излучателя, помещенного в структуру и находящегося в свободном пространстве, для центральной квантовой ямы первого 

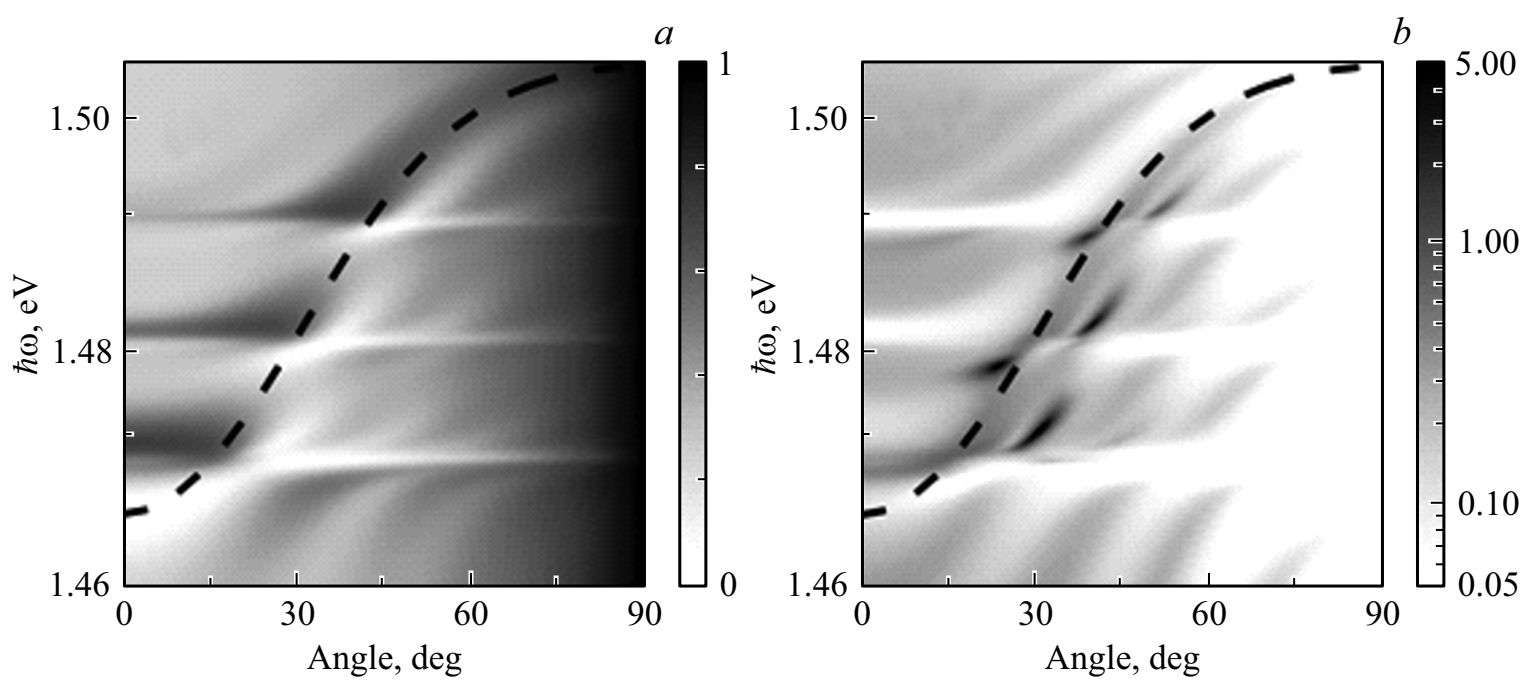

Рис. 3. Зависимости коэффициента отражения $(a)$ и модального фактора Парселла (b) от угла и частоты, рассчитанные методом $S$-квантования $[13,14]$ для света ТЕ-поляризации. Излучатель расположен в центральной квантовой яме первого периода структуры, и его дипольный момент параллелен слоям. Для сравнения штриховой линией показана зависимость, соответствующая брэгговскому условию (1).

периода, рассчитанного методом $S$-квантования [12-14]. Картины МФП для других квантовых ям в структуре похожи на картину для первой ямы. На картине МФП видны пики, располагающиеся вблизи точек на зависимости (1) на частотах экситонных резонансов (где значение МФП достигает нескольких единиц), но не для всех частот. Такое поведение МФП может объяснить экспериментально обнаруженное в работе [12] проявление сверхизлучательной моды только в малом интервале углов.

Отметим важную особенность, заключающуюся в том, что при точном совпадении брэгговской кривой с экситонными модами излучение оказывается подавленным. Такой эффект предсказан в работе [5], где был проведен подробный анализ оптических свойств периодических структур с квантовыми ямами и показано, что при возрастании числа периодов и точном выполнении брэгговского условия для толщины периода взаимодействие экситона с электромагнитным полем уменьшается.

Таким образом, проведенное измерение фотолюминесценции структуры с брэгговскими монослойными квантовыми ямами InAs с поверхности и с торца образца показало, что спектр люминесценции с торца образца (на который не влияет брэгговская интерференция между квантовыми ямами) практически не зависит от уровня накачки. В спектре излучения с поверхности образца появляются дополнительные моды. Теоретически рассчитанный модальный фактор Парселла имеет пики, положение которых находится вблизи значений, определяемых брэгговским условием, но не для всех значений углов и частот.

Авторы выражают благодарность Российскому научному фонду (грант 16-12-10503) и В.В. Кочаровскому за полезные обсуждения.

\section{Список литературы}

[1] E.M. Purcell, H.C. Torrey, R.V. Pound. Phys. Rev., 69, 37 (1946).

[2] В.П. Быков. ЖЭТФ, 35, 269 (1972).

[3] A. Yariv, P. Yeh. Optical waves in crystals. Propagation and control of laser radiation (N.Y., Wiley Interscience, 2003).

[4] E.L. Ivchenko, G.E. Pikus. Superlattices and Other Heterostructures: Symmetry and Optical Phenomena (Berlin, Springer Verlag, 1997).

[5] Е.Л. Ивченко, А.И. Несвижский, С. Йорда. ФТТ, 36, 1156 (1994).

[6] E.L. Ivchenko, A.I. Nesvizhskii, S. Jorda. Superlat. Microstruct., 16 (1), 17 (1994).

[7] E.L. Ivchenko, M.A. Kaliteevski, A.V. Kavokin, A.I. Nesvizhskii. J. Opt. Soc. Am. B, 13 (5), 1061 (1996).

[8] V.V. Chaldyshev, Y. Chen, A.N. Poddubny, A.P. Vasil'ev, Z. Liu. Appl. Phys. Lett., 98 (7), 73112 (2011).

[9] G. Pozina, M.A. Kaliteevski, E.N. Nikitina, D.V. Denisov, N.K. Polyakov, E.V. Pirogov, L.I. Gorai, A.R. Gubaidullin, K.A. Ivanov, N.A. Kaliteevskaya, A.Yu. Egorov, S.J. Clark. Sci. Rep., 5, 14911 (2015).

[10] G. Pozina, M.A. Kaliteevski, E.V. Nikitina, D.V. Denisov, N.K. Polyakov. Phys. Status Solidi B, 254 (4), 1600402 (2017).

[11] R.H. Dicke. Phys. Rev., 93 (1), 99 (1954).

[12] A.R. Gubaydullin, C. Symonds, J. Bellessa, K.A. Ivanov, E.D. Kolykhalova, M.E. Sasin, A. Lemaitre, P. Senellart, G. Pozina, M.A. Kaliteevski. Sci. Rep., 7, 9014 (2017).

[13] М.А. Калитеевский, В.А. Мазлин, К.А. Иванов, А.Р. Губайдуллин. Опт. и спектр., 119 (5), 810 (2015).

[14] M.A. Kaliteevski, A.R. Gubaydullin, K.A. Ivanov, V.A. Mazlin. Опт. и спектр., 121 (3), 446 (2016).

Редактор Л.В. Шаронова 


\section{Experimental study of spontaneous emission in the Bragg multiple quantum wells structure of InAs monolayers embedded in a GaAs matrix}

G. Pozina ${ }^{1}$, M.A. Kaliteevski ${ }^{2,3,4}$, E.V. Nikitina ${ }^{2}$, A.R. Gubaidullin ${ }^{2,4}$, K.A. Ivanov ${ }^{3}$, A.Yu. Egorov 3,4

${ }^{1}$ Department of Physics,

Chemistry and Biology (IFM), Linkoping University, S-58183 Linkoping, Sweden

${ }^{2}$ St. Petersburg Academic University, 194021 St. Petersburg, Russia

${ }^{3}$ loffe Institute,

194021 St. Petersburg, Russia

${ }^{4}$ ITMO University,

197101 St. Petersburg, Russia

Abstract Time-resolved photoluminescence of a Bragg structure of InAs-monolayer quantum wells in GaAs matrix was experimentally studied. Comparison of luminescence patterns from the side and from the surface of a sample showed that Braggtype ordering of quantum wells led to a substantial alteration of the photoluminescence spectra including appearance of additional radiative modes. The sample side spectrum contained a single line corresponding to the ground state of an exciton. In the surface spectrum at high excitation levels the new radiation line appeared whose frequency and propagation angle corresponded to the Bragg condition for quantum wells. The numerical calculation of the modal Purcell factor explained why the radiative emission amplification occured only at a set of specific angles and frequencies, as opposed to the whole range that satisfied the Bragg condition. 